\title{
PRÁTICAS ARTÍSTICAS PARA ENFRENTAMENTO DO ISOLAMENTO PELO IDOSO NO DOMICÍLIO DURANTE A PANDEMIA DA COVID-19
}

Raúl Fernando Guerrero-Castañeda' ORCID: 0000-0003-3996-5208

Tânia Maria de Oliva Menezes" ORCID: 0000-0001-5819-0570

Adriana Valéria da Silva Freitas" ORCID:0000-0003-1831-4537

Luana Araújo dos Reis"' ORCID: 0000-0002-9263-083X

'Universidad de Guanajuato. Celaya, Guanajuato, México.

"Universidade Federal da Bahia. Salvador, Bahia, Brasil.

II' Faculdade Independente do Nordeste. Vitória da Conquista, Bahia, Brasil.

Autor Correspondente: Raúl Fernando Guerrero Castañeda E-mail: ferxtom@hotmail.com

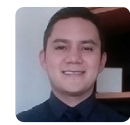

Como citar:

Guerrero-Castañeda RF, Menezes TMO, Freitas AVS, Reis LA. Práticas artísticas para enfrentamento do isolamento pelo idoso no domicílio durante a pandemia da covid-19. In: Santana RF (Org.). Enfermagem gerontologica no cuidado do idoso em tempos da COVID 19. 2.ed.rev. Brasilia, DF: Editora ABEn; 2020. p 47-53. (Serie Enfermagem e Pandemias, 2). https://doi.org/10.51234/aben.20.e02.c08

\section{INTRODUÇÃO}

No final de 2019 surgiu uma série de infecções respiratórias, sendo mais tarde declarado que estas eram causadas por um tipo de coronavírus denominado de COVID-19. Em 11 de março de 2020, a Organização Mundial da Saúde declarou essas infecções como uma pandemia global(1), o que levou à implementação de medidas de proteção e contingências de saúde com várias estratégias.

A transmissão do vírus é de pessoa para pessoa, especialmente em pessoas sintomáticas, então, o isolamento foi a maior estratégia para conter as infecções, e vários países implementaram esta medida para reduzir a propagação. Desses os idosos estão entre os grupos mais vulneráveis, devido a vários fatores como doenças crônicas, alterações no sistema imunológico, dependência, além de residirem em instituições e residências de longo prazo, na qual as chances de consequências negativas são maiores ${ }^{(2)}$.

Por esta razão, os idosos ficaram em situação de isolamento mais restrita, exigindo seu acompanhamento, e especial cuidado às suas características. Os idosos, em particular, devem ser atendidos com protocolos mais abrangentes para proteger sua integridade não apenas física, mas emocional e espiritualmente.

Pois, esta condição de isolamento pode favorecer o aparecimento de alterações na saúde mental dos idosos, identificando o aparecimento de sintomas depressivos, medo de contágio ou medo de morte, solidão, tristeza, sofrimento emocional e espiritual ${ }^{(3)}$. A pessoa idosa em solidão contempla uma redução em suas atividades, o contato social, familiar, atividade física, e até mesmo, as práticas religiosas, porque há pouco ou nenhum espaço para elas. Nesse contexto, a dinâmica da vida do idoso no cotidiano do seu envelhecimento ativo é afetada, podendo aparecer, posteriormente, consequências físicas, restrição da mobilidade, alteração na nutrição, aumento da sarcopenia, como consequência da diminuição da mobilidade. 
Por isso, é imperativo implementar estratégias de cuidado no domicílio que permitam promover a dinâmica da atividade do idoso, incentivando, por um lado, a mobilidade e a independência. Por outro, buscando atender as situações emocionais do idoso e até mesmo a espiritualidade, já que esta última se concentra não só nas práticas religiosas, mas, também, no encontro consigo mesmo e na busca de sentido no que está vivenciando.

Se considerarmos a enfermagem como a ciência do cuidado humano, e sob essa abordagem, pretendermos criar ambientes de cura, ou seja, momentos que permitam a expressão do idoso no seu cuidado pessoal, e ao mesmo tempo, favoreçam a integração do eu com o seu sentido de vida, teríamos uma ação apoiada na Teoria do Cuidado Humano de Watson ${ }^{(4)}$. Nessa, a enfermagem se propõe a promover momentos de cuidado que favoreçam a integração do corpo, mente e espírito do ser humano.

Nesse contexto, as práticas artísticas se apresentam como importante estratégia, pois são técnicas de arte incorporadas aos cuidados de enfermagem que, além de permitirem a expressão do ser humano através desta arte $^{(5)}$, buscam um objetivo terapêutico nos cuidados, a fim de favorecer a integração da saúde do ser humano.

Terapeuticamente, as práticas artísticas influenciam a saúde física, emocional, social e espiritual. Fisicamente, envolvem o corpo, o movimento, a prática e a coordenação; emocionalmente, favorecem a expressão de sentimentos e emoções e moldam a situação emocional, socialmente, favorecem a integração com o eu e os outros, permitem o reconhecimento do outro e buscam a integração; espiritualmente, se conectam com o sentido do universo e dos valores humanos.

Visto que os idosos estão isolados e enfrentam múltiplas alterações que desafiam sua saúde física, emocional e espiritual, é necessário promover práticas artísticas no cuidado domiciliar, pela enfermeira, mediante orientações para auxiliar a pessoa idosa a enfrentar o isolamento. Essas práticas contribuem com a promoção da saúde em todas as áreas e, ao mesmo tempo, o apoio à enfermagem holística na pessoa idosa isolada.

\section{OBJETIVO}

Relatar práticas artísticas para enfrentamento do isolamento pelo idoso no domicilio durante a pandemia da COVID-19.

\section{MÉTODO}

Trata-se de uma reflexão teórica, integrando a Teoria do Cuidado Humano (TCH) e as estratégias de práticas artísticas no cuidado domiciliar de idosos. A integração das práticas artísticas foi realizada com base na busca da literatura de artigos nacionais e internacionais, nos meses de maio e junho de 2020 e nas vivencias dos autores. Três temas principais foram identificados: 1. Isolamento e a dinâmica da vida; 2 . Jean Watson e favorecer os ambientes de healing no cuidado com terapias artísticas; 3 . Terapias artísticas em casa: intervenções propostas para enfermeiras.

\section{RESULTADOS}

\section{Isolamento e a dinâmica da vida}

O isolamento social e as práticas restritivas podem causar um impacto negativo em todos os aspectos da saúde e bem-estar ${ }^{(6)}$, especialmente em grupos de alto risco, como é o caso dos idosos, fazendo-se necessário a criação de uma rede de apoio psicossocial e a garantia de um ambiente seguro, que oportunize a estes a realização de atividades que preservem a saúde física, mental e espiritual.

Os idosos têm hábitos e um modo de vida peculiar de realização de atividades de vida diária e instrumental fragmentada com idas ao supermercado, compras e banco diariamente. Há ainda aqueles quer frequentam centros dia ou centros gerontológicos, onde realizam diversas atividades físicas, recreativas, culturais e 
esportivas que, por um lado, mantêm seu nível de independência e autonomia, e por outro, promovem sua saúde mental e relações humanas, ao encontrarem com seus amigos.

Com a pandemia e as medidas de isolamento, essa dinâmica de vida do idoso é interrompida. Eles têm que ficar em casa, às vezes com a família, o casal, ou, totalmente sozinhos, os que estão em casa, às vezes não têm o espaço, não há convivência que o motive e, por sua vez, a sua autonomia e independência tendem a se limitar.

Vale ressaltar que em países em desenvolvimento, muitos idosos vivem em condições precárias, devido ao baixo poder aquisitivo, com limitações de acesso aos serviços de saúde e de lazer. Sendo, portanto, necessária à criação de uma rede de apoio profissional e comunitária, que atue com a finalidade de reduzir o estresse, o conflito interpessoal e envolva o idoso em um projeto integrador, que o coloque no centro de um processo construtivo de ações que minimizem os impactos negativos à saúde.

Para muitos idosos, o envelhecimento pode estar associado a sentimentos negativos, tais como perda de sentido de vida, falta de utilidade familiar e social, e a solidão. As medidas de isolamento podem potencializar tais sentimentos, consentindo um idoso vulnerável ao desenvolvimento de sintomas depressivos. Visto que esses estão impedidos de manter a proximidade entre amigos, parentes e vizinhos, além de serem alvos frequentes de "memes" e infodemias em redes e mídias sociais, o que traz à luz uma realidade de enfrentamento inesperada.

Medidas simples e eficazes podem ser adotadas para minimizar os impactos gerados pelo isolamento social no domicílio, assegurando ao idoso a manutenção da autonomia, mobilidade, promovendo estímulos cognitivos e fortalecendo os laços familiares. Através do incentivo da manutenção das práticas religiosas, da realização de atividades físicas, de jogos de memória e de atividades lúdicas que promovam a saúde mental e o bem-estar geral. Especialmente em situação de confinamento, como é o caso do isolamento social imposto pela pandemia, além da interação social que pode ser estimulada através do uso de recursos tecnológicos.

Contudo, populações muito vulneráveis podem não ter amplo acesso à Internet e dispositivos eletrônicos que oferecem certos tipos de apoio social. Logo, a ação comunitária para aliviar o impacto psicológico do isolamento é ainda mais importante. Evitar comportamentos sedentários também é fundamental para a prevenção de problemas à saúde física, psicológica e social ${ }^{(7)}$. Desse modo, durante o isolamento social no domicílio é importante buscar estratégias que favoreçam o bem-estar individual e coletivo. Ser criativo e fazer uso de terapias artísticas são maneiras eficazes para manter vínculos afetivos e sociais significativos ${ }^{(8)}$, além de favorecer a manutenção da saúde física e mental dos idosos.

\section{Jean Watson: como favorecer os ambientes de healing no cuidado com terapias artísticas}

Ao longo dos anos, várias Teorias de Enfermagem foram desenvolvidas, algumas a um nível complexo, como a Teoria do Cuidado Humano. Entre seus conceitos, ela enfatiza que o cuidado de enfermagem é um ato que envolve subjetividade e intersubjetividade ${ }^{(9)}$. O primeiro, no sentido de que a pessoa que está sendo cuidada está envolvida em vários processos para entender sua situação de saúde. A intersubjetividade é criada no que Watson chama de Momento de Cuidado, onde tanto a pessoa que está sendo cuidada, quanto à pessoa que está cuidando, no caso à enfermeira, se encontram, interagem e forma um campo de energia desde o primeiro encontro.

Quando as pessoas passam por adoecimento que exige hospitalização, por exemplo, a enfermagem, em sua essência de cuidado humanizado deve reconhecer o outro na situação que se apresenta e compreender que não só exigirá terapia médica ou tratamentos alopáticos no processo de cuidado. A enfermeira deve atender a pessoa com postura empática, reconhecendo um ser humano e criando elementos em nível das intervenções que podem favorecer este espaço de reconstituição ou healing.

Watson aborda que o ser humano tem uma perspectiva transpessoal nessa relação de cuidados. O idoso, nessa pandemia, deve ficar em casa, porém, mesmo no conforto que pode ter no lar, situações difíceis parecem se confrontar, a exemplo do isolamento, solidão, redução da convivência, não poder praticar a religiosidade organizacional no templo religioso de sua crença. A partir desta visão de healing, a enfermeira aborda 
precisamente aqueles espaços onde não se limita à prática médica ou curativa. A enfermeira deve integrar ao seu conhecimento e prática profissional os valores humanos, para orientar o processo de cuidado. Ao levar em consideração esses aspectos, o atendimento torna-se um modo de vida que pode ser promovido pelas enfermeiras nos diversos ambientes, inclusive no lar.

A reflexão que leva a enfermeira a prática do cuidado como ato subjetivo de healing pode ser orientada pelo Processo Clinical Caritas ${ }^{(9)}$. São dez processos que permitem orientar este cuidado, com uma abordagem humanizada e aberta às diferentes possibilidades do mundo da vida. Alguns Processos Caritas estão ligados ao uso de terapias artísticas, pois promovem o encontro do ser humano, vão além do simples fato de se divertir ou ter uma abordagem curativa; têm em si um efeito terapêutico sobre o healing.

Em particular, o Processo 4"Refere-se ao desenvolvimento e manutenção de relacionamento de confiança"; o Processo 6, a "Resolução criativa de problemas através do processo de cuidado: uso pleno do eu e da arte das práticas de cuidado-reconstituição, através de todas as formas de conhecimento"; e o Processo 8 refere-se à "Criação de um ambiente de healing em todos os níveis"; ambiente sutil para uma presença energética autêntica e carinhosa.

Colocando o Processo 4 nessa discussão, a enfermeira em ambientes domiciliares e ILPIs tem um chamado para a prática do cuidado humanizado, abrindo seu campo de ação e não fechando o cuidado ao simples ambiente hospitalar. A enfermeira deve trabalhar com os idosos em um processo comunicativo aberto, não o fechando para entrevistas curtas. Ela deve conhecer sua história de vida, saber o impacto que a pandemia e a quarentena têm em suas vidas e seu processo de autocuidado, suas crenças, valores, medos e apreensões. A enfermeira deve se colocar na posição de escutar ativamente e facilitar no confinamento a independência, autonomia e, acima de tudo, aceitação do momento presente.

O primeiro passo para contribuir no desenvolvimento do idoso em isolamento social é o Processo 6, que aborda precisamente a prática da arte do cuidado como uma forma de praticar o healing. A enfermeira deve contribuir para criar o ambiente de healing para os idosos, que lhes permite encontrar nas artes uma terapia, momento lúdico, estímulo cognitivo e oportunidade para enfrentar de forma saudável o momento presente. Não é um processo fácil, nem que aconteça de forma instantânea, mas é dinâmico, de aprendizagem mútua e desenvolvimento pessoal. As artes são uma forma de cuidado de enfermagem, são terapêuticas e promovem ambientes de healing.

Neste processo, busca-se justamente estimular práticas artísticas de forma criativa, permitindo a expressão de sentimentos, ideias e emoções. Estas práticas favorecem aquele ambiente de healing para os idosos. Eles apoiam o confronto do isolamento, quando estão cercados pela família. O contato é favorecido e a presença do outro é sentida no acompanhamento.

O Processo 8 fala da reconstituição do ser, favorecendo com as terapias artísticas um ambiente de energia positiva, um ambiente que favoreça a expressão, o uso do corpo como meio de expressão, a linguagem, o sentimento de ser útil e com independência na realização de atividades, reforça o sentimento de pertença e independência do homem idoso.

Como se pode observar, o Processo Clinical Caritas pode servir de apoio aos cuidados de enfermagem na promoção de ambientes de healing. Nesse momento, todos aqueles idosos em diferentes ambientes sofrem um processo difícil, suas rotinas têm sido interrompidas e aumenta o medo de contágio, o distanciamento das pessoas queridas. As terapias artísticas valorizam o valor estético dos cuidados e da pessoa idosa, suas histórias de vida são capturadas nelas e promovem aquele ambiente de presença tão necessário. Essa presença vai além do contato físico, é o sentido subjetivo de estar-presente.

\section{Terapias Artísticas em Casa: Intervenções propostas para Enfermeiras}

No isolamento social indicado durante a pandemia da COVID-19, as pessoas idosas devem ser incentivadas a fazerem atividades em casa, para que possam conseguir lidar com as restrições de contato promovidas pelo 
distanciamento social. Dentre as possibilidades de atividades que poderão contribuir de maneira terapêutica, e que podem ser promovidas pela enfermeira no cuidado para criar ambientes de healing e promoção de saúde destacam-se: a música, a dança, o desenho, a escrita.

Música: $\mathrm{A}$ inserção da arte no contexto de cuidados à saúde é recomendada internacionalmente ${ }^{(10)}$. A música estimula áreas do cérebro, como o sistema límbico, que é a região responsável pelo ânimo, encorajamento, afetividade, emoções e comportamento social. Ao se escutar qualquer melodia, pode-se ter a sensação de bem-estar e prazer, que poderá promover mudanças físicas e psicológicas no indivíduo ${ }^{16}$.

Outro efeito da música é a aproximação com a espiritualidade. Diante do estresse, isolamento social e medo de que a pessoa idosa vive na pandemia, ouvir música possibilita transcender as dificuldades, esquecendo-as momentaneamente o que vivencia e encontrar sentido no cotidiano da existência. Estudo refere que a utilização da música como uma estratégia complementar de cuidado é um recurso que estimula o indivíduo no direcionamento de um comportamento mais resiliente diante às adversidades, ao estimular a espiritualidade dos pacientes frente ao medo e à angústia sentidos ${ }^{(10)}$.

A enfermeira deve conhecer a preferência musical do idoso, estimulando a escuta várias vezes durante o dia, principalmente quando no domicílio, para que possa se ocupar neste momento de isolamento social. Ouvir música estimula a dança, para aqueles que gostam, prática artística que será discutida a seguir.

Dança: A dança tem efeitos positivos na vida da pessoa idosa. Estudo refere que a dança de salão deve ser indicada para proporcionar melhora no equilíbrio e no desempenho motor nas atividades de vida diária em indivíduos idosos. Alem disso, é uma forma de prevenção e controle de agravamentos de doenças demenciais e motoras já existentes no paciente idoso ${ }^{(11)}$. Se a pessoa idosa tiver um parceiro no domicílio, pode convidar para dançar. Quando se trata de adolescente, talvez ele não se disponibilize e considere estranho, porque a dança de salão é mais comum entre pessoas mais velhas, contudo, a enfermeira pode colocar para a família a importância de uma atividade física como a dança, para que haja colaboração com o bem-estar da pessoa idosa, inclusive, se ela tinha prática desta atividade antes da pandemia.

Com a manutenção da pessoa idosa no domicílio nesse momento, a dança se apresenta como outro recurso que a enfermeira pode dispor para estímulo não só da atividade física, como também, ocupação do tempo livre. A dança, como um meio de promoção da saúde, no qual o cuidado realizado pelo profissional, em especial pelo de enfermagem, deve incentivar essa prática com o objetivo de conectar corpo e mente. Tem funcionado como um canal de expressão de sentimentos e anseios, concorrendo, assim, para o enfrentamento de tabus, mitos e preconceitos sociais relativos ao envelhecimento ${ }^{(11)}$.

Desenho: $O$ trabalho com arteterapia em que utilizam o desenho pode conseguir que conteúdos simbólicos venham à tona de forma rápida e fácil(12). Por isso, a arte é um recurso revelador, quando existem situações emocionais traumáticas ou limitantes.

É comum encontrar estudos que abordam o uso do desenho para atividades com crianças e adolescentes. No que diz respeito às pessoas idosas, estudo afirma que o desenho é uma atividade artística mais apreciada por aquelas com demência. A arte evidenciada nos desenhos proporciona uma maneira de expressar a emoção, principalmente quando o sujeito não consegue verbalizar seus sentimentos ${ }^{(13)}$.

Dessa maneira, a enfermeira pode inserir em seu plano de cuidados atividades artísticas, através de desenhos, para que as pessoas idosas possam realizar em momentos de lazer. Pode, ainda, orientar familiares e cuidadores, para que utilizem esse recurso como forma de interação com os idosos, tendo sempre o princípio do respeito pela sua autonomia no aceite dessa ferramenta de cuidado.

Escrita: A escrita é uma das diversas formas de expressão artística. Sendo assim, é possível usar a escrita como um recurso de cuidado de enfermagem, pois, através dela, poderá ser realizado o estímulo a memória, aos aspectos cognitivos e, ainda, as habilidades motoras.

Nessa perspectiva, estudo realizado através de um projeto de extensão com pessoas idosas, afirma que algumas delas apesar de referirem que pouco sabiam escrever, quando motivadas a atividade em que precisavam 
usar a escrita para colocarem em cartazes emoções percebidas ao ouvirem músicas, acabavam expressando sentimentos e subjetividades ${ }^{(14)}$. Além de trabalhar a percepção, pensamento, raciocínio, criatividade e memória.

Assim, o fazer artístico poderá estimular diversas funções e habilidades integrando os sistemas: sensorial, motor, emocional e cognitivo. Dessa forma, a arte é capaz de despertar a motivação e resgatar a autoestima daqueles que a utilizam, ampliando a percepção e exteriorização de sentimentos ${ }^{(15)}$.

A proposta é que a pessoa idosa possa ter algumas estratégias como escrever cartas para seus amigos ou familiares, escrever um diário sobre momentos especiais de sua vida no cotidiano, escrever aquelas histórias que ele se lembra com amor, ou até poemas. A ideia é fornecer elementos como papel e caneta, ou estimular, para que a pessoa idosa use sua imaginação, reminiscência e escreva o que ele considera significativo.

\section{Limitações do estudo}

A produção científica sobre o uso de terapias artísticas na enfermagem ainda é incipiente e o Cuidado Humano postula as artes e humanidades como um recurso que deve ser o conhecimento da enfermagem, sendo uma das formas a ser utilizada, especialmente nesse momento de pandemia.

\section{Contribuição para Enfermagem}

A contribuição desta reflexão para a enfermagem é centrar o papel da enfermeira como criadora de ambientes de cuidado, que pode ser promovido no domicílio da pessoa idosa, ajudando-a a lidar com o isolamento social imposto durante a pandemia da COVID-19. Também, propõe estratégias de terapias artísticas que, além dos benefícios físicos e cognitivos, ajudam a criar ambientes de healing, que permite a pessoa idosa o encontro com a sua espiritualidade e consigo mesmo, equilíbrio entre mente, corpo e espírito, além de serem terapias simples, que podem ser adaptadas a cada situação particular.

\section{CONSIDERAÇÕES FINAIS}

A enfermeira deve buscar o desenvolvimento de habilidades artísticas para auxiliar melhor a pessoa idosa que permanece isolada no domicílio durante a pandemia da COVID-19. Ainda não faz parte do seu cenário de prática, entretanto, diante dos benefícios que a terapia artística apresenta, torna-se imprescindível um novo olhar para práticas ainda incipientes na sua atuação profissional.

As terapias artísticas podem fomentar um ambiente de cuidado que não só promove a estimulação cognitiva, a mobilidade e a saúde mental, mas, também é um recurso lúdico e recreativo, que promove o reconhecimento da pessoa e aumenta sua sensação de bem-estar.

$\mathrm{O}$ isolamento social requer a proposta de formas de cuidados que ajudem a promover a saúde física, mental e espiritual da pessoa idosa, sendo possível a implementação dessas estratégias pelas enfermeiras em ambiente de cuidado domiciliar.

\section{AGRADECIMENTO:}

Ao Departamento Científico de Enfermagem Gerontológica da ABEn Nacional.

\section{REFERÊNCIAS}

1. Cucinotta D, Vanelli M. WHO declares COVID-19 a pandemic. Acta Biomed; 2020;91(1): 157-160. doi:10.23750/abm.v91i1.9397

2. Gálvez AMP, Romero BB, Trigo SB, Serrano ML. Personas mayores, dependencia y vulnerabilidad en la pandemia por coronavirus: emergencia de una integración social y sanitaria. Enferm Clínica. 2020; doi:10.1016/j.enfcli.2020.05.004 
3. Ribot RV, Chang PN, González CAL. Efectos de la COVID-19 en la salud mental de la población. Rev haban cienc méd [Internet]. 2020 [cited 2020 Jun 15];19(0): e3307. Available from: http://www.revhabanera.sld.cu/index.php/rhab/article/view/3307

4. Norman V, Rossillo K, Skelton K. Creating Healing Environments Through the Theory of Caring. AORN Journal. 2016;104(5): 401-409. doi:10.1016/J.AORN.2016.09.006

5. Ching-Teng Y, Ya-Ping Y, Yu-Chia C. Positive effects of art therapy on depression and self-esteem of older adults in nursing homes. Soc Work Health Care. 2019;58(3): 324-338. doi:10.1080/00981389.2018.1564108

6. Xyrichis A, Hext G, Clark LL. Beyond restraint: Raising awareness of restrictive practices in acute care settings. Int. J. Nurs. 2018;86: A1-A2. doi:10.1016/j.ijnurstu.2018.06.006

7. Maher JP, Conroy DE. Daily Life Satisfaction in Older Adults as a Function of (In)Activity. J Gerontol B-Psychol. 2016;72(4): 593-602. doi:10.1093/geronb/gbv086

8. Vieira C, Franco OH, Gómez Restrepo C, Abel T. COVID-19: The forgotten priorities of the pandemic. Maturitas. 2020;136: 38-41. doi:10.1016/j.maturitas.2020.04.004

9. Watson J. Nursing. The Philosophy and Science of Caring. Boulder: University Press of Colorado; 2008.

10. Nunes EC, Oliveira FA, Cunha JXP, Reis SO, Meira GG, Szylit R. A música como instrumento de cuidado transpessoal percepções de indivíduos hospitalizados assistidos na extensão universitária. Esc Anna Nery. 2019;24(2): e20190165. doi:10.1590/2177-9465-EAN-2019-0165

11. Borges EGS, Vale RGS, Pernambuco CS, Cader SA, Sá SPC, Pinto FM, et al. Efeitos da dança no equilíbrio postural, na cognição e na autonomia funcional de idosos. Rev Bras Enferm. 2018;71(suppl 5):2436-43. doi: 10.1590/0034-7167-2017-0253

12. Rodrigues HMM, Oliveira NML, Câmara RC, Oliveira AO. Arteterapia, um importante recurso psicoterápico. Anais X Simpac. [Internet] 2018 [cited 2020 Jun 15];10(1): 611-616. Available from: https://academico.univicosa.com.br/revista/index.php/ RevistaSimpac/article/view/1106

13. López ML. Arte y fotografía ánalogico-digital, herramientas de intervención social y empoderamiento para personas con demencia tipo Alzhéimer. INFAD. 2016;2(1): 67-80. doi:10.17060/ijodaep.2015.n1.v2.12

14. Medeiros LF, Medeiros ACB, Oliveira ICS, Costa LMT, Araújo GC, Chagas ABO. Compartilhando cuidado e afetividade entre idosos e estudantes-narrativas de um projeto de extensão. Interfaces-Revista de Extensão da UFMG. [Internet] 2019 [cited 2020 Jun 17]; 7(1). Available from: https://periodicos.ufmg.br/index.php/revistainterfaces/article/view/19078

15. França DCH, Pinto KG, Rodrigues RAL, Lino ALP, Honorio MS, Carvalho ELF. Análise bioestatística da adesão da arteterapia como meio para alcançar a cura e tratamento de doenças no estado de Goiás. Revista Interação Interdisciplinar. [Internet] 2019 [cited 2020 Jun 17]; 3(1): 118-128. Available from: http://publicacoes.unifimes.edu.br/index.php/interacao/article/view/596 